\section{BRAZIULIAN JOURNAL \\ OF MIEDICAL AND BIOLOGICAL RESFARCH}

www.bjournal.com.br
ISSN 0100-879X

Volume 42 (10) 870-992 October 2009

BIOMEDICAL SCIENCES

AND

CLINICAL INVESTIGATION

Braz J Med Biol Res, October 2009, Volume 42(10) 892-901

Treatment of hemorrhagic shock with hypertonic saline solution modulates the inflammatory response to live bacteria in lungs

C.I. Fernandes, F. Llimona, L.C. Godoy, E.M. Negri, V. Pontieri, A.I. Moretti, T.R. Fernandes,

F.G. Soriano, I.T. Velasco and H.P. Souza

The Brazilian Journal of Medical and Biological Research is partially financed by
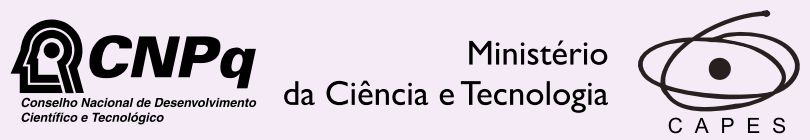

Ministério da Educação

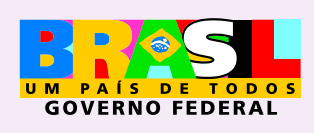

Institutional Sponsors 


\title{
Treatment of hemorrhagic shock with hypertonic saline solution modulates the inflammatory response to live bacteria in lungs
}

\author{
C.I. Fernandes*, F. Llimona*, L.C. Godoy, E.M. Negri, V. Pontieri, A.I. Moretti, \\ T.R. Fernandes, F.G. Soriano, I.T. Velasco and H.P. Souza \\ Disciplina de Emergências Clínicas, Departamento de Clínica Médica (LIM51), Faculdade de Medicina, \\ Universidade de São Paulo, São Paulo, SP, Brasil \\ Correspondence to: H.P. Souza, Departamento de Clínica Médica (LIM51), USP, Av. Dr. Arnaldo, 455, \\ Sala 3134, 01246-903 São Paulo, SP, Brasil \\ Fax: +55-11-3066-7170. E-mail: heraldo@emercli.fm.usp.br
}

\begin{abstract}
Shock and resuscitation render patients more susceptible to acute lung injury due to an exacerbated immune response to subsequent inflammatory stimuli. To study the role of innate immunity in this situation, we investigated acute lung injury in an experimental model of ischemia-reperfusion (I-R) followed by an early challenge with live bacteria. Conscious rats $(\mathrm{N}=8$ in each group) were submitted to controlled hemorrhage and resuscitated with isotonic saline ( $\mathrm{SS}, 0.9 \% \mathrm{NaCl}$ ) or hypertonic saline (HS, $7.5 \% \mathrm{NaCl}$ ) solution, followed by intratracheal or intraperitoneal inoculation of Escherichia coli. After infection, toll-like receptor (TLR) 2 and 4 mRNA expression was monitored by RT-PCR in infected tissues. Plasma levels of tumor necrosis factor $\alpha$ and interleukins 6 and 10 were determined by ELISA. All animals showed similar hemodynamic variables, with mean arterial pressure decreasing to nearly $40 \mathrm{mmHg}$ after bleeding. HS or SS used as resuscitation fluid yielded equal hemodynamic results. Intratracheal $E$. coli inoculation per se induced a marked neutrophil infiltration in septa and inside the alveoli, while intraperitoneal inoculation-associated neutrophils and edema were restricted to the interseptal space. Previous I-R enhanced lung neutrophil infiltration upon bacterial challenge when SS was used as reperfusion fluid, whereas neutrophil influx was unchanged in HS-treated animals. No difference in TLR expression or cytokine secretion was detected between groups receiving HS or SS. We conclude that HS is effective in reducing the early inflammatory response to infection after I-R, and that this phenomenon is achieved by modulation of factors other than expression of innate immunity components.
\end{abstract}

Key words: Toll-like receptors; Immune system; Pneumonia; Escherichia coli; Neutrophils

${ }^{*}$ These authors contributed equally to this study.

Research supported by FAPESP (\#02/02930-0 and \#03/12325-0) and Fundação Faculdade de Medicina; Direx LIMs. C.I. Fernandes and F. Llimona are recipients of Doctorate fellowships from CAPES and FAPESP, respectively.

Received January 19, 2009. Accepted April 28, 2009. Available online September 4, 2009.

\section{Introduction}

Intravascular fluid resuscitation is the consensual treatment for patients with hypovolemic shock (1). This lifesaving procedure may, on the other hand, induce ischemia and reperfusion (I-R) injury in cells of virtually any vital organ (2). I-R injury is, by itself, a potent inflammatory trigger, increasing cytokine release, reactive oxygen species generation, and endothelial activation, with consequent nitric oxide production and expression of adhesion molecules (2). In addition, I-R may prime the organism for an exaggerated inflammatory response (massive tissue- 
cellular infiltration and edema) to a secondary stimulus such as infection, with devastating consequences (3). These so-called two-hit injuries occur with remarkable frequency in trauma patients who suffered hemodynamic instability (4). The lungs are, most commonly, the target of this second injury (5), morphologically characterized by alveolar and interstitial fluid accumulation, alveolar hemorrhage, fibrin deposition, and lung neutrophil sequestration (6). Accumulation of neutrophils in the lung vasculature, interstitium, and alveolar space is considered to be a critical event in the pathophysiologic process and has been the target of various preventive strategies (7).

The mechanisms by which I-R modulates immunity leading to exacerbated pulmonary responses to a second challenge are not completely understood. In a study from our laboratory (8) using a controlled hemorrhage model of shock in rats, we showed that acute lung injury occurs after reperfusion, with generation of cytokines and reactive oxygen species. Interestingly, when hypertonic saline solution $(7.5 \% \mathrm{NaCl})$ was used as reperfusion fluid, lung injury was attenuated and heat shock proteins were upregulated early after reperfusion. However, even though the innate immune response is believed to play a role in this phenomenon (3), aspects of this nature were not investigated in that study.

In the present study, we sought to evaluate to what extent innate immunity components, such as toll-like receptors (TLRs) and cytokines, contribute to an exaggerated inflammatory response to infection following I-R. TLRs are the main pattern-recognition receptors in mammals, recognizing conserved molecular patterns shared by large groups of microorganisms (9). The activation of TLRs triggers a complex series of events that culminate in enhanced transcription of proinflammatory genes, whose ultimate goal is to initiate the mechanisms that counteract infection (10). We hypothesized that I-R primes the innate immune system to overreact upon a bacterial challenge, and that this preconditioning would consist in altered levels of TLRs and proinflammatory cytokines. To test this hypothesis, we submitted rats to global I-R injury, infected them with Escherichia coli and evaluated the effects of reperfusion with isotonic versus hypertonic fluid on the profile of inflammatory infiltrating cells, expression of TLRs and cytokines.

\section{Material and Methods}

The study was approved by the Ethics Committee for Human and Animal Research of the Faculdade de Medicina, Universidade de São Paulo. All animals were treated according to the institutional norms for laboratory animal care.

\section{Hemorrhagic shock model}

Male Wistar rats weighing 280 to $320 \mathrm{~g}$ were housed in a controlled environment and had free access to water and normal rat chow (Nuvital, Nuvital Nutrientes Ltda., Brazil). Twenty-four hours before the experiments, the animals were weighed and anesthetized with an intraperitoneal injection of $50 \mathrm{mg} / \mathrm{kg}$ ketamine and $50 \mathrm{mg} / \mathrm{kg}$ xylazine. The left femoral artery and vein were cannulated with PE-10 Tygon catheters that were exposed on the dorsal region and identified.

The animals were conscious during the shock and resuscitation experiment. No signs of pain or discomfort were observed. The arterial catheter was connected to a pressure transducer for continuous measurement of mean arterial blood pressure and heart rate. This catheter was also used for blood withdrawal and induction of hemorrhagic shock. The venous catheter was used for volume replacement. Hemorrhagic shock was obtained by blood withdrawal $(31 \mathrm{~mL} / \mathrm{kg}$ ) divided into 6 equal episodes during a 30 -min period. All animals were maintained with a mean arterial pressure of $40 \mathrm{mmHg}$ for $60 \mathrm{~min}$ and then divided randomly into two groups of 48 rats. One group received hypertonic solution ( $\mathrm{HS}, 7.5 \% \mathrm{NaCl}, 4 \mathrm{~mL} / \mathrm{kg}$ ), while other group received isotonic solution (SS, $0.9 \% \mathrm{NaCl}, 34 \mathrm{~mL} /$ $\mathrm{kg}$, corresponding to the same amount of sodium administered to the first group). Also, a group of 24 animals was not submitted to bleeding. Resuscitation fluid (isotonic or hypertonic solution) was infused for $5 \mathrm{~min}$, after which the mean arterial pressure reached the values observed before bleeding. The animals were then kept sheltered and warm until the time for the second manipulation.

\section{Bacterial inoculation}

Escherichia coli serotype O111-EPEC was a gift from Dr. Murilo Chiamolera (Emergency Medicine Department, Faculdade de Medicina, Universidade de São Paulo). Bacteria were stored at $-80^{\circ} \mathrm{C}$ and thawed the day before the experiments. The $E$. coli inoculum was prepared in phosphate-buffered saline (PBS) from frozen stock.

Two hours after resuscitation, the animals were again randomized and anesthetized and an intratracheal tube was inserted. The rats were then placed in the supine position on a $60^{\circ}$ inclined board. Using an intratracheal tube, $200 \mu \mathrm{L}$ E. coli suspension containing $1.0 \times 10^{5} \mathrm{CFU}$ or PBS was instilled. Another group was submitted to intraperitoneal inoculation of the same bacterial suspension. The experimental groups obtained after these procedures are listed in Table 1. The animals were sacrificed by a pentobarbital overdose $4 \mathrm{~h}$ after these procedures. The right lungs were used for histological analysis while the left lungs were used to analyze mRNA expression. 


\section{Mortality}

Groups of 6 animals each were submitted to the procedures described above and, after bacterial inoculation, they were returned to the animal facility for mortality follow-up. Mortality was checked four times a day for 1 week.

\section{Total RNA isolation and RT-PCR}

Lung fragments were homogenized in TRIzol reagent and vortexed after the addition of $1 / 10$ volume of chloroform. After incubating the mixture on ice for $15 \mathrm{~min}$, samples were centrifuged at $7500 \mathrm{~g}$ for $15 \mathrm{~min}$ at $4^{\circ} \mathrm{C}$. The aqueous phase was collected and RNA was precipitated by mixing with the same volume of isopropyl alcohol, followed by 30 min incubation on ice and centrifugation at $7500 \mathrm{~g}$ for $15 \mathrm{~min}$ at $4^{\circ} \mathrm{C}$. Precipitated RNA pellets were washed once with $70 \%$ ethyl alcohol and dissolved in diethylene pyrocarbonate-containing water. RNA concentration was determined by absorbance at $260 \mathrm{~nm}$ and its integrity was confirmed by electrophoresis on $1 \%$ agarose gels stained with $0.1 \mathrm{mg} / \mathrm{L}$ ethidium bromide. One migrogram mRNA was converted to complementary DNA (cDNA) by reverse transcription (RT) reaction performed in a $20-\mu \mathrm{L}$ RT reaction mixture containing $10 \mu \mathrm{L}$ Improm II reverse transcriptase (Promega, USA), $4.0 \mu \mathrm{L} 5 \mathrm{X}$ reaction buffer (Promega), $1.0 \mu \mathrm{L}$ dNTP mixture (10 mM; Invitrogen, Brazil), $0.5 \mu \mathrm{L}$ RNAase inhibitor (40 U/ $\mu \mathrm{L}$; Promega), and $1.0 \mu \mathrm{L}$ oligo dT (50 $\mu \mathrm{M}$ Promega) in water. The reaction was performed at $42^{\circ} \mathrm{C}$ for 42 min followed by $70^{\circ} \mathrm{C}$ for $15 \mathrm{~min}$. PCR was carried out with $1.0 \mu \mathrm{L}$ RT products as templates. The amplified products were analyzed by ethidium bromide-stained agarose gel electrophoresis. Annealing temperature and cycling parameters for each target mRNA were set so that the bands used for density measurements were not saturated. The PCR products on each band were analyzed by densitometry using the Image Gene Tools software (Syngene, USA). The PCR primer sequences were: TLR4 sense: 5'AAGAGCTGG ACCTGGAC3'; TLR4 antisense: 5'GAAATGCTACAG TGGCTACC3'; TLR2 sense: 5'CAGCTGGAGAACT CTGACCC3'; TLR2 antisense: 5'CAAAGAGCCTGAAGT GGGAG3'.

\section{Histological analysis}

After fixation in $10 \%$ formalin, lung tissue was embedded in paraffin and cut into $4-$ to $6-\mu \mathrm{m}$ sections. The sections were stained with hematoxylin and eosin and analyzed by light microscopy. Neutrophil infiltration was reported as the number of multilobular-nucleus cells divided by the area evaluated. A total of ten randomly selected fields were analyzed in each tissue section. Monocytes and elongated cells (epithelial cells, fibroblasts, muscle cells, etc.) were also counted. Alveolar septum area was determined with a digital image analysis system and specific software (Leica Q-Win 2002, Germany) at 400X magnification. The images were generated by a microscope (Leica) connected to a camera (Sony Trinitron CCD, Sony, Japan) and fed into a computer through a frame grabber for online processing. The threshold for lung tissue was established after the adjustment of contrast. The area occupied by lung tissue was determined by digital densitometric recognition. Bronchi and blood vessels were carefully avoided during the measurements. The results are reported as numbers of neutrophils, monocytes and elongated cells divided by septal area in each field measured. Two blind observers performed cell counts and the agreement between them was $>90 \%$.

\section{Cytokine measurement}

Blood samples were collected at the beginning of hemorrhage induction and just before sacrifice. Plasma cytokines (IL-10, IL-6, and TNF- $\alpha$ ) were measured by ELISA according to manufacturer instructions (R\&D Technologies, USA).

\section{Statistical analysis}

Numerical data are reported as means \pm SEM. Comparisons between multiple groups were performed by analysis of variance (ANOVA) and individual groups were compared by the Tukey test. A $P$ value of $<0.05$ was considered to be significant. 


\section{Results}

\section{Hemodynamic data}

Arterial blood pressure and heart rate were similar at the beginning of the experiments for all groups. Animals were conscious, and compensatory mechanisms could be activated. After hemorrhage, blood pressure and heart rate were also comparable for all groups. At the end of bleeding, animals were hypoactive and searching for shelter in their bedding. No differences in behavior were detected among groups.

Table 2 shows the evolution of blood pressure during the procedures in all experimental groups. There were no hemodynamic differences between animals receiving SS or HS as resuscitation fluid. Both groups recovered blood pressure very quickly after fluid infusion, and maintained these parameters until further manipulation.

\section{Mortality}

An early $10 \%$ mortality rate was recorded among animals submitted to controlled hemorrhage. All of these casualties occurred during the period between the end of the bleeding procedure and the beginning of resuscitation. There was no correlation between mortality and the fluid used for reperfusion.

After reperfusion and bacterial inoculation, we observed changes in behavior, with the animals being hypoactive and seeking shelter. This behavior lasted for approximately $24 \mathrm{~h}$. Water and food ingestion was decreased during this period. Two days after bacterial inoculation all animals returned to their normal activities. No difference was observed between the groups that were challenged with bacteria in the peritoneal cavity or the trachea, or between the animals submitted or not to hemorrhage before bacterial inoculation.

Up to one week after infection, none of the animals had died, indicating that the adopted experimental conditions led to controllable, sublethal pathophysiological alterations in the animals.

\section{Acute lung injury}

We next focused on the acute lung injury observed after I-R, followed or not by a second bacterial challenge. Initially, we observed that I-R injury by itself was able to induce an inflammatory reaction in lungs. In Figure 1, SHAM represents the normal lung architecture. Thin septa and a few macrophages can be observed. After ischemia and reperfusion with SS, perivascular edema and polymorphonuclear cells infiltrating the septa were observed. No neutrophils were detected inside the alveoli (Figure 1, $\mathrm{SS})$. When reperfusion was carried out with HS, these findings were less evident in comparison to animals that received SS, there were fewer neutrophils, as well as less enlargement of the septa and exudate formation (Figure 1, HS).

To determine whether I-R could modulate TLR4 function, we challenged animals with Gram-negative bacteria inoculated either intratracheally or into the peritoneal cavity. Injection of $E$. coli into the lungs led to a marked inflammatory cellular infiltrate inside the septa, with predominance of neutrophils, which was also observed in the alveolar spaces, characteristic findings of bacterial pneumonia (Figure 1, EC-T). When bacteria were inoculated into the trachea after shock and reperfusion with SS, a larger neutrophil infiltrate was observed inside the alveoli, with abundant exudate and thickening of septal space (Figure 1, SEC-T). On the other hand, when HS was used as the reperfusion fluid, fewer neutrophils were present in the septa and almost no cells were detected inside the alveoli (Figure 1, HEC-T, and Figure 2B). Injection of E. coli bacteria into the peritoneal cavity and further pulmonary analysis revealed the presence of neutrophils inside the septa and perivascular spaces, but not inside the alveoli (Figure 1, EC-P). Cellular infiltration and interstitial edema were more exuberant in the group resuscitated with SS (Figure 1, SEC-P), while once again the group that received $\mathrm{HS}$ displayed milder inflammatory features (Figure 1, HEC$\mathrm{P})$.

Neutrophils infiltrating the pulmonary tissue after I-R were quantified and the results are shown in Figure 2. I-R by itself caused a significantly increased infiltration of neutrophils into the interseptal space when SS was employed, whereas the cellular infiltration in the lungs of HS-treated rats was lower and statistically identical to that of the control group. Furthermore, a similar profile regard-

Data are reported as means \pm SEM blood pressure $(\mathrm{mmHg})$. There were no statistically significant differences among the four groups submitted to bleeding For group definition, see legend to Table 1 . 
Figure 1. Lung histology. Panel SHAM shows the histology of a normal lung, showing thin septa and a few infiltrating inflammatory cells in the vascular bed or perivascular space. SS = Lungs after hemorrhage and resuscitation with isotonic saline solution; a prominent cellular infiltrate is observed, mainly inside the septa, but no neutrophils are detected inside the alveoli; $\mathrm{HS}=$ hypertonic saline was used as reperfusion fluid; relatively fewer infiltrating cells, less septal enlargement and exudate formation; EC-T = Escherichia coli inoculation into the trachea induced a marked infiltration of polymorphonuclear cells inside the septa and alveolar space, a finding characteristic of pneumonia; SEC-T = bacterial challenge performed after hemorrhage and reperfusion with isotonic saline; a large neutrophilic infiltrate was observed inside the alveoli, with abundant exudate and enlargement of septal wall; HEC-T = inoculation of $E$. coli after shock and reperfusion with hypertonic solution led to a smaller inflammatory infiltrate compared to SEC$\mathrm{T}$, with virtually no neutrophils inside the alveoli; EC-P = intraperitoneal $E$. coli administration led to a small inflammatory infiltrate concentrated mainly around blood vessels; septa were enlarged and no neutrophils were observed inside the alveoli. Similar findings were present in animals reperfused with isotonic saline (SEC-P). However, the magnitude of the inflammatory process was larger. HEC-P = Reperfusion with hypertonic saline down-regulates the inflammatory process in response to $E$. coli inoculation into the peritoneum, preserving the pulmonary morphological characteristics. A representative picture of 3 animals per group is shown. Hematoxylin-eosin staining. Magnification bars $=100 \mu \mathrm{m}$.

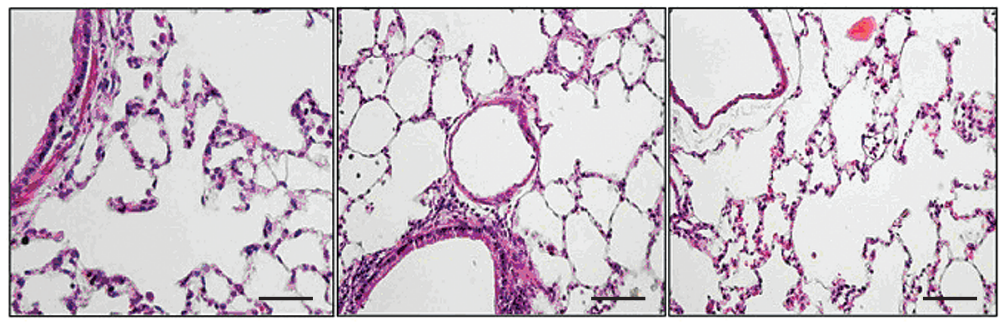

SHAM SS HS

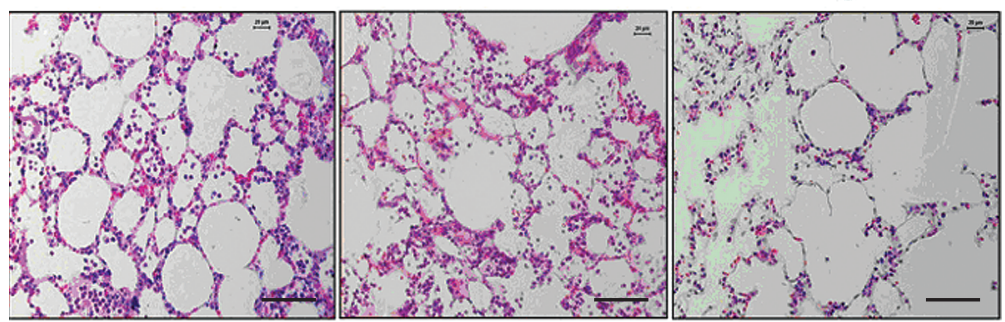
EC-T SEC-T HEC-T

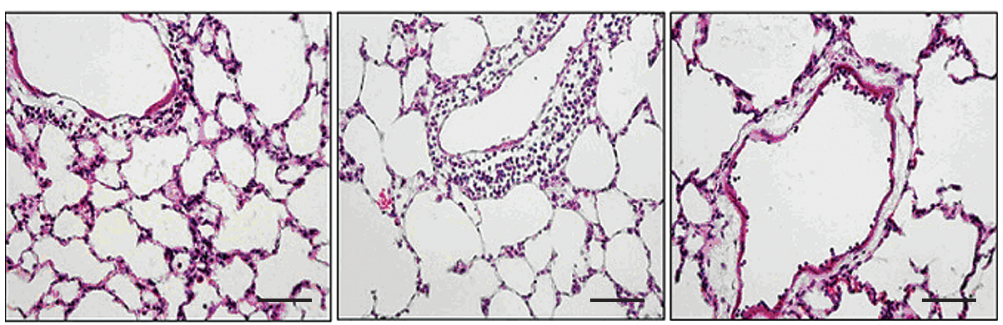

HEC-P
A

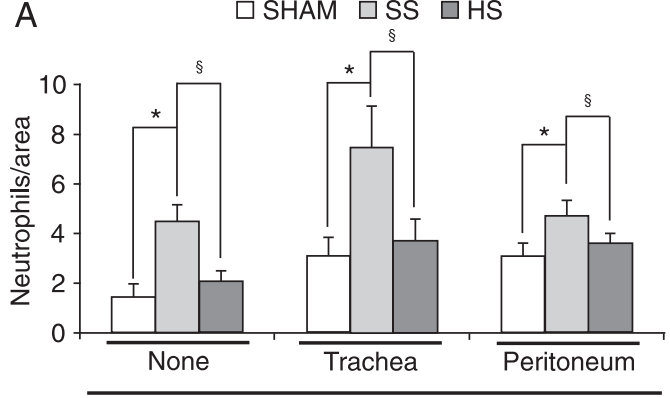

Site of bacterial inoculation

B

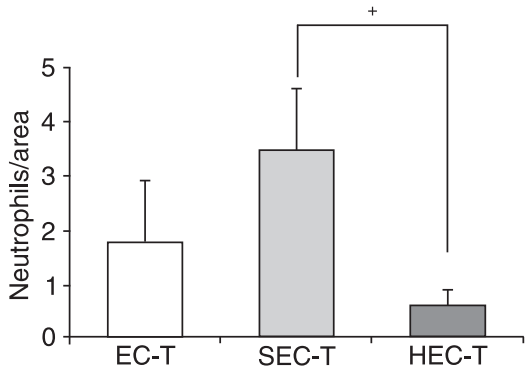

Figure 2. Neutrophil infiltration in lungs. $A$, This figure is a quantitative representation of the histological findings shown in Figure 1. Ischemia-reperfusion with isotonic saline by itself increased neutrophil infiltration in septal spaces; when hypertonic solution was used, no alteration occurred. Escherichia coli inoculation into the trachea induced neutrophil accumulation in the septal space, which was further enhanced by previous hemorrhage and reperfusion with isotonic saline solution, but not with hypertonic solution. When E. coli was inoculated intraperitoneally, a neutrophil infiltrate was still present in the lungs, although the effect of previous reperfusion was less evident. $B$, Alveolar neutrophils were present only when $E$. coli was inoculated into the trachea. Previous reperfusion with saline solution enhanced this cellular infiltration, while the treatment with hypertonic solution abrogated it. For abbreviations, see legend to Figure 1. Data are representative of at least 5 animals in each group and are reported as means \pm SEM. ${ }^{*} \mathrm{P}<0.05$ vs SHAM; $\$ \mathrm{P}<0.05$ vs SSTrachea or SS-Peritoneum; ${ }^{+} \mathrm{P}<0.05$ vs SEC-T (ANOVA). 
ing the pulmonary influx of neutrophils was observed when bacteria were inoculated into the trachea or the peritoneal cavity after I-R. In addition, the presence of neutrophils in the alveolar space was observed only when $E$. coli was inoculated intratracheally. Lungs from rats treated with HS before the bacterial challenge exhibited fewer neutrophils infiltrating both intra- and extra-alveolar spaces.

In all of the experimental situations described above, reperfusion with HS solution was able to decrease polymorphonuclear recruitment to the pulmonary tissue, as compared to isotonic saline solution. Because these events took place early after I-R and/or bacterial inoculation, we hypothesized that innate immunity components might be involved in this phenomenon, and thus we investigated pathways involved in pathogen recognition (TLRs) and inflammatory signal amplification (cytokines).

\section{Toll-like receptor expression}

In order to determine whether I-R could affect pathogen recognition and hence predispose lungs to a more severe injury after a bacterial challenge, we analyzed the transcription of mRNA for TLRs 2 and 4 in the lung tissue.

As shown in Figure 3A, I-R per se did not affect transcription of the TLR2 gene. Interestingly, in the absence of $\mathrm{I}-\mathrm{R}$, exposure to Gram-negative $E$. coli enhances mRNA for TLR2, which is described as a receptor for Grampositive bacteria, both when inoculation was in the trachea and in the peritoneum. In addition, previous I-R boosted TLR2 gene transcription even further when bacteria were inoculated into the trachea, regardless of the solution used for volume reconstitution. Intraperitoneal challenge after I$R$ did not affect TLR2 gene transcription.

Regarding the expression of the TLR4 gene, even though small differences could be detected among the experimental groups, there was wide variability; hence no statistical significant difference could be established (Figure 3B).

\section{Cytokine measurements}

Cytokines are soluble mediators of the inflammatory response, responsible in part for the amplification or restraint of the process. Thus, we investigated whether I-R injury could modulate the secretion of cytokines with proinflammatory (TNF- $\alpha$ and IL-6) or anti-inflammatory (IL-10) effects so that a later response to a bacterial challenge could be impacted.

Plasma TNF- $\alpha$ levels were increased after bacterial injection regardless of the route of inoculation. I-R, be it by itself or in association with bacterial challenge, did not significantly change TNF- $\alpha$ levels in the circulation (Figure 4A). A similar profile was observed for IL-6 levels, with a marked increase detected after bacterial challenge, while
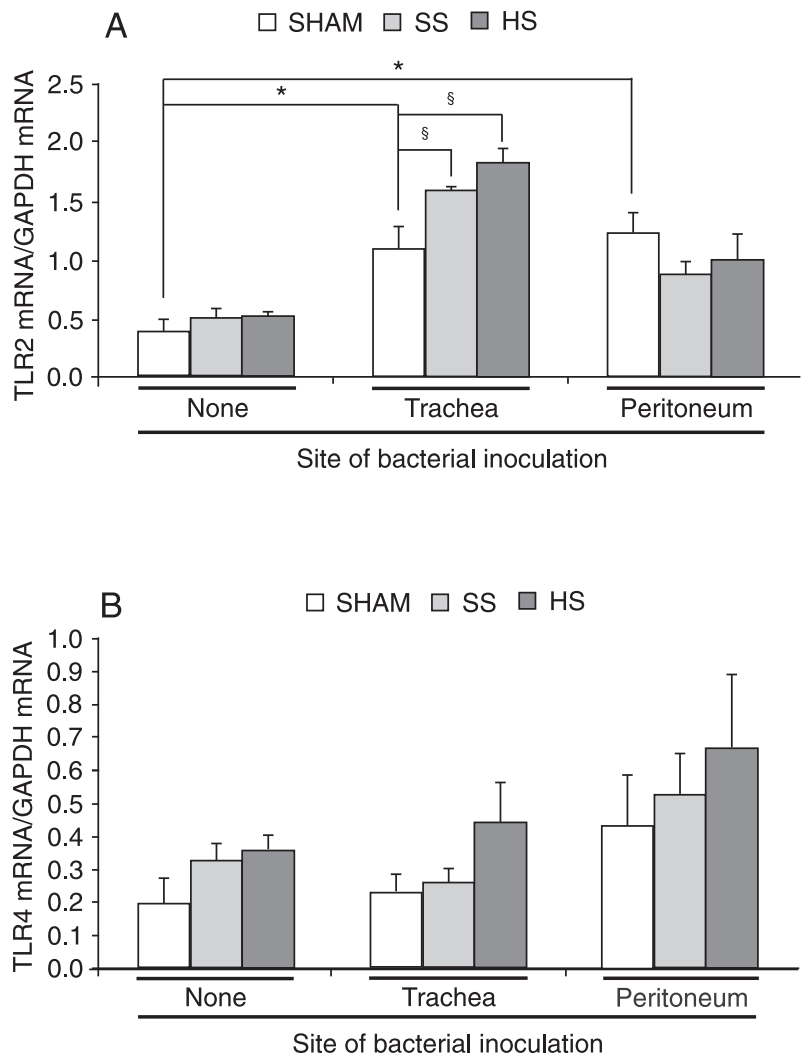

Figure 3. Toll-like receptor (TLR) gene transcription. $A$, Ischemia-reperfusion alone did not affect TLR2 mRNA levels, as analyzed by RT-PCR. Exposure of rats to Escherichia coli via the trachea, but not the peritoneum, enhanced TLR2 gene transcription, which was further amplified by previous ischemia-reperfusion. Data are reported as means \pm SEM. $\mathrm{N}=6$ for each group. ${ }^{*} \mathrm{P}<0.05$ vs SHAM and no infection; $\$ \mathrm{P}<0.05$ vs SHAM and tracheal inoculation (ANOVA). $B$, No differences were detected in TLR4 gene transcription, as measured by RT-PCR, when ischemia-reperfusion was performed or when animals were challenged with bacteria. GAPDH = glyceraldehyde 3-phosphate dehydrogenase. For other abbreviations, see legend to Figure 1.

the previous occurrence of I-R seemed to decrease IL-6 levels only slightly compared to bacterial challenge alone (Figure 4B).

An increase was detected in IL-10 levels after bacterial inoculation, which was abolished by previous I-R (Figure $4 C)$. Intriguingly, I-R by itself promoted enhanced IL-10 secretion when no further bacterial challenge was performed.

\section{Discussion}

Infection following severe trauma is a public health problem and the main cause of later death in affected 

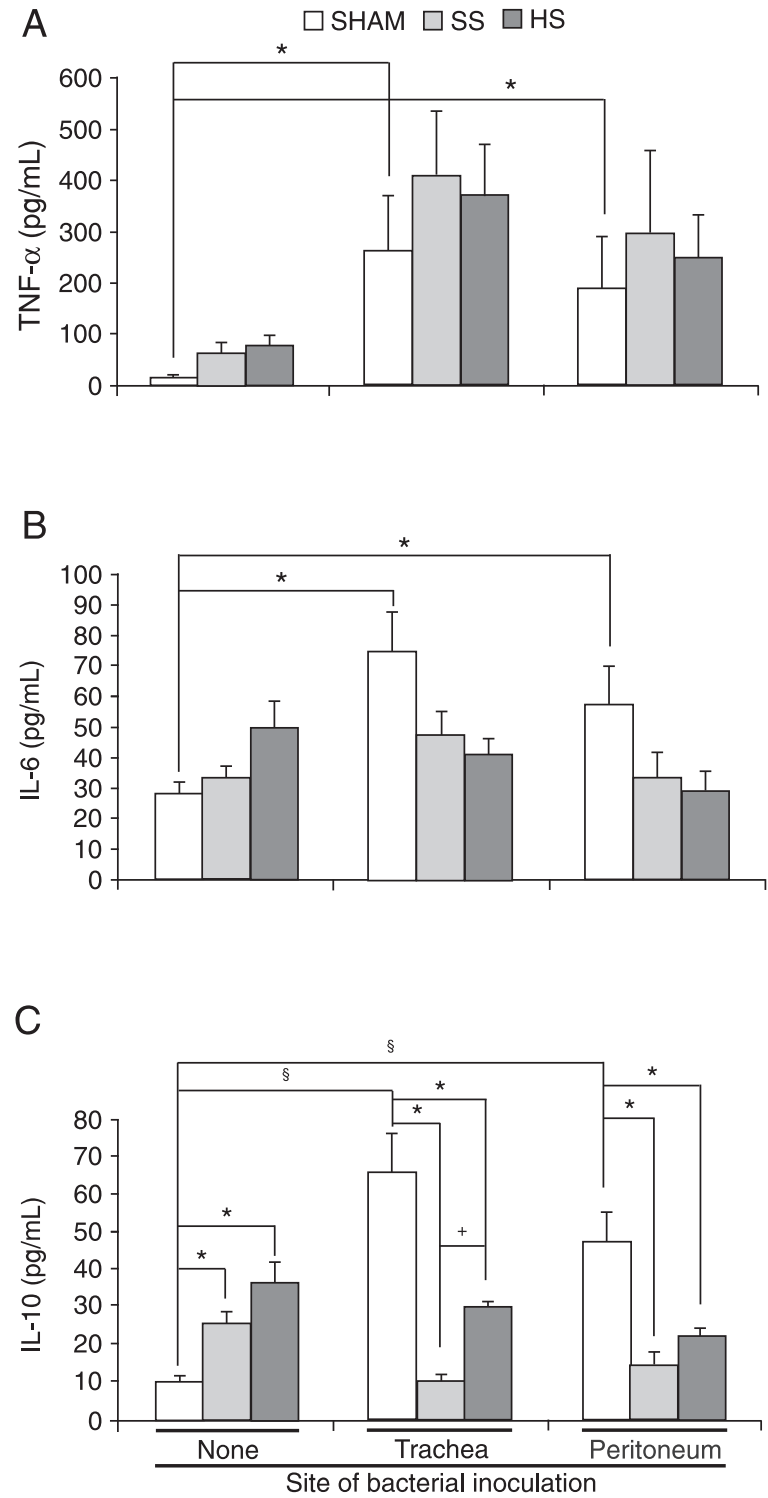

Figure 4. Plasma cytokine levels. $A$, After bacterial inoculation into the trachea or the peritoneal cavity, increased TNF- $\alpha$ secretion was observed. Ischemia-reperfusion did not affect TNF- $\alpha$ levels even when it was followed by bacterial challenge. ${ }^{*} \mathrm{P}<$ 0.05 (ANOVA). B, Bacterial challenge induced increased IL-6 secretion. Slightly decreased levels of IL-6 were detected when bacterial inoculation was performed after ischemia-reperfusion, although these differences were not statistically significant. $C$, IL-10 levels were increased by ischemia-reperfusion alone. Increased IL-10 levels were also detected after bacterial inoculation into the trachea or the peritoneal cavity. Interestingly, previous ischemia-reperfusion blunted IL-10 secretion after bacterial challenge, a phenomenon that was less evident when hypertonic saline was used as reperfusion fluid. Data are reported as means \pm SEM. $\mathrm{N}=6$ for each group. ${ }^{*} \mathrm{P}<0.05$ vs SHAM and no inoculation; $\mathrm{SP}<0.05$ vs SHAM; ${ }^{+} \mathrm{P}<0.05$ vs SS (ANOVA). patients (11). In spite of all the improvements in intensive care, morbidity is still high and the best treatment seems to be prevention (4). The I-R injury associated with the treatment of hemorrhagic shock often primes the lungs to an exaggerated inflammatory response upon a second stimulus, usually of an infectious nature, and may lead to respiratory failure (7). In the present study, we provide additional evidence supporting the notion that HS has antiinflammatory effects when used in hemorrhagic shock resuscitation. In our experimental model of controlled hemorrhage in rats, when HS solution was used as the reperfusion fluid, acute lung inflammation was less severe, as indicated by a milder interstitial edema and fewer neutrophils infiltrating the perivascular space and alveoli. This phenomenon seems not to be associated with altered levels of TLRs or inflammatory cytokines.

The use of small volumes of $\mathrm{HS}$ solution $(7.5 \% \mathrm{NaCl}$, $2400 \mathrm{mOsm}$ ) in experimental hemorrhagic shock models was described in the early 1980 s (12) and proved to be as effective as larger volumes of isotonic solution in restoring hemodynamic parameters, arterial pressure and tissue perfusion (12-15). It also has the advantages of requiring a shorter infusion time (crucial for treatment of patients with severe bleeding), being easier to stock and displaying fewer volume-related complications (e.g., cardiac pulmonary edema) (16).

Recently, experimental models of hemorrhagic shock have shown that resuscitation with HS favorably modulates the outcome of I-R injury (8,17-23). Among other effects, resuscitation with HS inhibits the respiratory burst in neutrophils (24), minimizes the expression of adhesion molecules in neutrophils $(20,23,25)$ and in endothelial cells (26), increases IL-10 secretion (an anti-inflammatory cytokine), and decreases TNF- $\alpha$ generation in rat macrophages exposed to lipopolysaccharide (LPS) (19). Milder neutrophil infiltration and decreased intercellular adhesion molecule-1 expression after shock and resuscitation with HS have also been documented (17). In this latter study, the histological findings were similar to those obtained in the present investigation, though the observations were made $24 \mathrm{~h}$ after resuscitation, which suggests that the antiinflammatory benefits of HS are chronically sustained.

We initially hypothesized that the I-R injury would precondition the innate immune system to mount an exacerbated reaction upon a further stimulus such as a bacterial infection. Therefore, we exposed animals to live bacteria to investigate changes in innate immunity, particularly TLR4 function, after I-R injury. Although acute lung injury was milder in animals receiving HS, no differences in TLR expression could be detected between these animals and those treated with isotonic saline. This finding suggests 
that the $\mathrm{I}-\mathrm{R}$ injury process does not modulate a further inflammatory response by altering the expression of TLR4.

Regarding the lack of alterations in TLR4 among our experimental groups, our findings differ from those of another report showing that intratracheal LPS injection induced a reduction in lung tissue and alveolar macrophage levels of TLR4 mRNA, while previous shock and resuscitation prevented a TLR4 decrease when lungs were exposed to LPS (27). Different experimental conditions may account for these discrepancies, the most important being the fact that our model relies on infection with live bacteria, which implies that a much more complex process is under way and may even involve the participation of other TLRs (10).

We observed that TLR2 was increased in lungs after intratracheal challenge with bacteria. Even though TLR2 is not involved in the recognition of $E$. coli, the bacterium used in our study, cooperative mechanisms have been described among TLRs (28). For example, in murine microglial cells challenged with LPS and peptidoglycan, TLR4 is absolutely necessary to engage the innate immune response, while TLR2 participates in the regulation of genes encoding TNF- $\alpha$ and IL-12 during severe endotoxemia (29). Such collaboration between TLR4 and TLR2 may be crucial for the transition from the innate to the adaptive immunity mechanisms in infected animals (29). Moreover, TLR2 up-regulation might derive from a nonspecific response to other products derived from whole bacteria, since this receptor is not supposed to recognize LPS (30).

We also evaluated the effect of $\mathrm{I}-\mathrm{R}$ and infection on circulating cytokines in our experimental model. As expected, the bacterial challenge per seaugmented TNF- $\alpha$, IL6 and IL-10 levels. In animals submitted to previous I-R, however, the pattern of circulating cytokines was different. While TNF- $\alpha$ levels did not change when compared to bacterial inoculation alone, IL-6 and IL-10 levels were lower when animals were submitted to I-R before exposure to bacteria. This finding is intriguing since these cytokines have opposite roles in inflammation (31). Perhaps, because IL-6 is known to stimulate IL-10 synthesis (32), lower levels of this inflammatory factor may account for the decreased amounts of IL-10 under our experimental conditions.

While TNF- $\alpha$ and IL- 6 circulating levels were the same regardless of the kind of replacement solution employed after shock, IL-10 concentration was higher when reperfusion was done with $\mathrm{HS}$ infusion. Even though this increase is not dramatic, it seems plausible that, along with other factors not investigated herein, IL-10 may contribute to the effects observed in the animals due to its anti-inflammatory properties (33). It is not completely clear how hypertonic solutions affect gene transcription and cytokine synthesis. Nonetheless, it is well known that hypertonicity can affect the expression of a series of genes involved in volume regulation (34). It can also affect some important signaling cascades involved in the response to stress (35), especially in neutrophils $(36,37)$. Therefore, it is tempting to speculate that resuscitation with HS could ultimately modulate some of the signaling pathways regulating the inflammatory response in the lungs.

No consensus exists among experts about the best animal model for hemorrhage and resuscitation research (38). Conscious animal models, such as ours, are preferred because they minimize anesthesia artifacts like blockade of the sympathoexcitatory response (39). As discussed in previous studies from our group (8), the bleeding rate and volume are uniform for all animals in this model, as confirmed by the monitoring of hemodynamic data. Moreover, lethality in our model was not high and deaths occurred exclusively during the early shock period, before the animals were treated with reperfusion fluids or challenged with bacteria, and therefore we understand that the mortality observed should not be a factor to be considered in the analysis of our results. Since the objective of this study was to investigate the pathophysiology of I-R injury and not the effectiveness of the treatment, we conclude that the SS concentration used in resuscitation is the main factor affecting the course of the inflammatory response in this experimental model.

In conclusion, although the mechanism of action remains to be elucidated, the beneficial effects of HS solutions in the treatment of hemorrhagic shock are undeniable, as the present results seem to corroborate. Allied to the convenient fact that no side effects of the use of HS solutions have been described so far, future studies addressing other components involved in the regulation of the inflammatory response in this context may provide useful tools for the control of reactions to a secondary infectious stimulus in trauma and shock patients.

\section{Acknowledgments}

We are grateful to Ms. Fatima Abatepaulo for preparing the tissue sections and to Dr. Murilo Chiamolera, Emergency Medicine Department, Faculdade de Medicina, USP, for advice with bacterial culture. 


\section{References}

1. Dirksen MT, Laarman GJ, Simoons ML, Duncker DJ. Reperfusion injury in humans: a review of clinical trials on reperfusion injury inhibitory strategies. Cardiovasc Res 2007; 74: 343-355.

2. Anaya-Prado R, Toledo-Pereyra LH, Lentsch AB, Ward PA. Ischemia/reperfusion injury. J Surg Res 2002; 105: 248258.

3. Rotstein OD. Modeling the two-hit hypothesis for evaluating strategies to prevent organ injury after shock/resuscitation. J Trauma 2003; 54: S203-S206.

4. Nast-Kolb D, Aufmkolk M, Rucholtz S, Obertacke U, Waydhas $\mathrm{C}$. Multiple organ failure still a major cause of morbidity but not mortality in blunt multiple trauma. $J$ Trauma 2001; 51: 835-841.

5. Moore FA, McKinley BA, Moore EE. The next generation in shock resuscitation. Lancet 2004; 363: 1988-1996.

6. Fernandes AB, Zin WA, Rocco PR. Corticosteroids in acute respiratory distress syndrome. Braz J Med Biol Res 2005; 38: 147-159.

7. Rocco PR, Zin WA. Pulmonary and extrapulmonary acute respiratory distress syndrome: are they different? Curr Opin Crit Care 2005; 11: 10-17.

8. Fernandes TR, Pontieri V, Moretti Al, Teixeira DO, Abatepaulo $F$, Soriano FG, et al. Hypertonic saline solution increases the expression of heat shock protein 70 and improves lung inflammation early after reperfusion in a rodent model of controlled hemorrhage. Shock 2007; 27: 172-178.

9. Janeway CA Jr, Medzhitov R. Innate immune recognition. Annu Rev Immunol 2002; 20: 197-216.

10. An H, Yu Y, Zhang M, Xu H, Qi R, Yan X, et al. Involvement of ERK, p38 and NF-kappaB signal transduction in regulation of TLR2, TLR4 and TLR9 gene expression induced by lipopolysaccharide in mouse dendritic cells. Immunology 2002; 106: 38-45.

11. Osborn TM, Tracy JK, Dunne JR, Pasquale M, Napolitano LM. Epidemiology of sepsis in patients with traumatic injury. Crit Care Med 2004; 32: 2234-2240.

12. Velasco IT, Pontieri V, Rocha e Silva M Jr, Lopes OU. Hyperosmotic $\mathrm{NaCl}$ and severe hemorrhagic shock. Am J Physiol 1980; 239: H664-H673.

13. Velasco IT, Rocha e Silva M, Oliveira MA, Oliveira MA, Silva RI. Hypertonic and hyperoncotic resuscitation from severe hemorrhagic shock in dogs: a comparative study. Crit Care Med 1989; 17: 261-264.

14. Velasco IT, Rocha-e-Silva M. Hypertonic saline resuscitation is prevented by intracerebroventricular saralasin but not by captopril. Braz J Med Biol Res 1989; 22: 237-239.

15. Rocha e Silva M, Velasco IT, Nogueira da Silva RI, Oliveira MA, Negraes GA, Oliveira MA. Hyperosmotic sodium salts reverse severe hemorrhagic shock: other solutes do not. Am J Physiol 1987; 253: H751-H762.

16. Rocha-e-Silva M, Poli de Figueiredo LF. Small volume hypertonic resuscitation of circulatory shock. Clinics 2005; 60: 159-172.

17. Yada-Langui MM, Anjos-Valotta EA, Sannomiya $P$, Rocha e Silva M, Coimbra R. Resuscitation affects microcirculatory polymorphonuclear leukocyte behavior after hemorrhagic shock: role of hypertonic saline and pentoxifylline. Exp Biol Med 2004; 229: 684-693.
18. Rizoli SB, Kapus A, Parodo J, Rotstein OD. Hypertonicity prevents lipopolysaccharide-stimulated CD11b/CD18 expression in human neutrophils in vitro: role for p38 inhibition. J Trauma 1999; 46: 794-798.

19. Powers KA, Woo J, Khadaroo RG, Papia G, Kapus A, Rotstein OD. Hypertonic resuscitation of hemorrhagic shock upregulates the anti-inflammatory response by alveolar macrophages. Surgery 2003; 134: 312-318.

20. Angle N, Cabello-Passini R, Hoyt DB, Loomis WH, Shreve A, Namiki $S$, et al. Hypertonic saline infusion: can it regulate human neutrophil function? Shock 2000; 14: 503-508.

21. Murao $Y$, Loomis W, Wolf $P$, Hoyt DB, Junger WG. Effect of dose of hypertonic saline on its potential to prevent lung tissue damage in a mouse model of hemorrhagic shock. Shock 2003; 20: 29-34.

22. Murao $Y$, Hoyt DB, Loomis W, Namiki S, Patel N, Wolf $P$, et al. Does the timing of hypertonic saline resuscitation affect its potential to prevent lung damage? Shock 2000; 14: 1823.

23. Rizoli SB, Kapus A, Fan J, Li YH, Marshall JC, Rotstein OD. Immunomodulatory effects of hypertonic resuscitation on the development of lung inflammation following hemorrhagic shock. J Immunol 1998; 161: 6288-6296.

24. Angle N, Hoyt DB, Coimbra R, Liu F, Herdon-Remelius C, Loomis $\mathrm{W}$, et al. Hypertonic saline resuscitation diminishes lung injury by suppressing neutrophil activation after hemorrhagic shock. Shock 1998; 9: 164-170.

25. Deitch EA, Shi HP, Feketeova E, Hauser CJ, Xu DZ. Hypertonic saline resuscitation limits neutrophil activation after trauma-hemorrhagic shock. Shock 2003; 19: 328-333.

26. Oreopoulos GD, Hamilton J, Rizoli SB, Fan J, Lu Z, Li YH, et al. In vivo and in vitro modulation of intercellular adhesion molecule (ICAM)-1 expression by hypertonicity. Shock 2000; 14: 409-414.

27. Fan J, Kapus A, Marsden PA, Li YH, Oreopoulos G, Marshall $\mathrm{JC}$, et al. Regulation of Toll-like receptor 4 expression in the lung following hemorrhagic shock and lipopolysaccharide. $J$ Immunol 2002; 168: 5252-5259.

28. Ozinsky A, Underhill DM, Fontenot JD, Hajjar AM, Smith $\mathrm{KD}$, Wilson $\mathrm{CB}$, et al. The repertoire for pattern recognition of pathogens by the innate immune system is defined by cooperation between toll-like receptors. Proc Natl Acad Sci U S A 2000; 97: 13766-13771.

29. Laflamme N, Echchannaoui H, Landmann R, Rivest S. Cooperation between toll-like receptor 2 and 4 in the brain of mice challenged with cell wall components derived from Gram-negative and Gram-positive bacteria. Eur J Immunol 2003; 33: 1127-1138.

30. Klinman DM, Yi AK, Beaucage SL, Conover J, Krieg AM. CpG motifs present in bacteria DNA rapidly induce lymphocytes to secrete interleukin 6 , interleukin 12, and interferon gamma. Proc Natl Acad Sci U S A 1996; 93: 2879-2883.

31. Dinarello CA. Proinflammatory cytokines. Chest 2000; 118 : 503-508.

32. Daftarian PM, Kumar A, Kryworuchko M, az-Mitoma F. IL10 production is enhanced in human T cells by IL-12 and IL6 and in monocytes by tumor necrosis factor-alpha. $J$ Immunol 1996; 157: 12-20.

33. Khadaroo RG, Fan J, Powers KA, Fann B, Kapus A, 
Rotstein OD. Impaired induction of IL-10 expression in the lung following hemorrhagic shock. Shock 2004; 22: 333339.

34. Burg MB, Kwon ED, Kultz D. Osmotic regulation of gene expression. FASEB J 1996; 10: 1598-1606.

35. Kultz D, Burg M. Evolution of osmotic stress signaling via MAP kinase cascades. J Exp Biol 1998; 201: 3015-3021.

36. Junger WG, Hoyt DB, Davis RE, Herdon-Remelius C, Namiki $\mathrm{S}$, Junger $\mathrm{H}$, et al. Hypertonicity regulates the function of human neutrophils by modulating chemoattractant receptor signaling and activating mitogen-activated protein kinase p38. J Clin Invest 1998; 101: 2768-2779.
37. Junger WG, Hoyt DB, Hamreus M, Liu FC, Herdon-Remelius C, Junger W, et al. Hypertonic saline activates protein tyrosine kinases and mitogen-activated protein kinase p38 in T-cells. J Trauma 1997; 42: 437-443.

38. Majde JA. Animal models for hemorrhage and resuscitation research. J Trauma 2003; 54: S100-S105.

39. Mackway-Jones K, Foex BA, Kirkman E, Little RA. Modification of the cardiovascular response to hemorrhage by somatic afferent nerve stimulation with special reference to gut and skeletal muscle blood flow. J Trauma 1999; 47: 481485. 